\title{
A recent review on 2019 novel coronavirus outbreak
}

\section{Bipin Shaji*, Abisri Suresh, Nimitha Vasanth, Sharon Mary Stanly}

Department of Pharmacy Practice, Karavali College of Pharmacy, Mangalore, Karnataka, India

Received: 11 November 2020

Accepted: 15 December 2020

\author{
*Correspondence: \\ Bipin Shaji, \\ Email: bipinshaji111@gmail.com
}

Copyright: (C) the author(s), publisher and licensee Medip Academy. This is an open-access article distributed under the terms of the Creative Commons Attribution Non-Commercial License, which permits unrestricted non-commercial use, distribution, and reproduction in any medium, provided the original work is properly cited.

\begin{abstract}
SARS-CoV2, a single-stranded RNA virus that can cause a wide array of clinical manifestations ranging from mild to severe (respiratory failure). The spread of SARS-CoV2 has now become uncontrollable leading to a pandemic. The infection is usually transmitting through cough droplets and sneeze. The main clinical manifestations of the disease are similar to common respiratory tract infections and may become fatal after the development of symptoms such as severe dyspnea, low $\mathrm{PaO}_{2} / \mathrm{FiO}_{2}$ (fraction of inspired oxygen) ratio, and severe decline in blood oxygen saturation. Current diagnostic tools employed at the moment include time-consuming NAAT (nucleic acid amplification test). Recent investigations and researches are aimed at rapid serological testing. Real-time reverse transcription-polymerase chain reaction (rRT- PCR) is the standard method of testing, using respiratory samples obtained by the nasopharyngeal swab. Medications such as darunavir, ribavirin, remdesivir, interferon, and lopinavir/ritonavir combination therapy were used for the management of the infection. Social distancing, use of protective masks, isolation of the infected persons and maintaining personal hygiene helps in the prevention of the disease.
\end{abstract}

Keywords: COVID-19, SARS-Cov2, Pandemic, Infection

\section{INTRODUCTION}

A coronavirus is a group of viruses that belongs to the family Coronaviridae. These are single-stranded, pleomorphic RNA viruses of size 80-160 nm, enveloped with +27 to $+32 \mathrm{~kb}$ polarity. Coronavirus is a zoonotic contagious agent with a wide set of clinical features. Coronaviruses are the provenience of a broad spectrum of clinical manifestations that originates from the common URTIs (upper respiratory tract infections) and influenza to more severe diseases like SARS (severe acute respiratory syndrome) and MERS (middle East respiratory syndrome). It can also affect respiratory, gastrointestinal, hepatic, and neurologic functions. ${ }^{1,2}$

SARS CoV2 (severe acute respiratory syndrome coronavirus 2) is a new emergent in the family of coronaviruses. Novel coronavirus 2019, identified in the Wuhan city of China on $31^{\text {st }}$ December 2019 was initially identified as an outbreak of pneumonia with a mysterious cause.

On $12^{\text {th }}$ January 2020, the virus was recognized as SARS $\mathrm{CoV} 2$ as it is genetically similar to SARS-like coronavirus. Since COVID-19 has metastasized worldwide WHO declared COVID-19 as a pandemic and declared it as a public health emergency of international concern (PHEIC). ${ }^{3}$ Patients detected with COVID-19 are known to come across with mild to moderate respiratory illness and can be fatal in people with other co-morbidities such as cardiovascular disease, diabetes, cancer, renal or liver damage, or any long-standing respiratory illness such as COPD, asthma, pulmonary fibrosis, emphysema, bronchitis etc.

\section{EPIDEMIOLOGY}

According to the current reports (until November 3, 2020), active COVID-19 cases worldwide were 12,146,669 (99\% 
have the mild condition and $1 \%$ serious). As per (Figure $1)$, the graph shows a peak rise in the active cases reported daily. The total number of patients recovered were $34,160,322$ and deaths were $1,214,122$. The total number of active COVID-19 cases in India were 48,268 as shown in the graph (Figure 2).

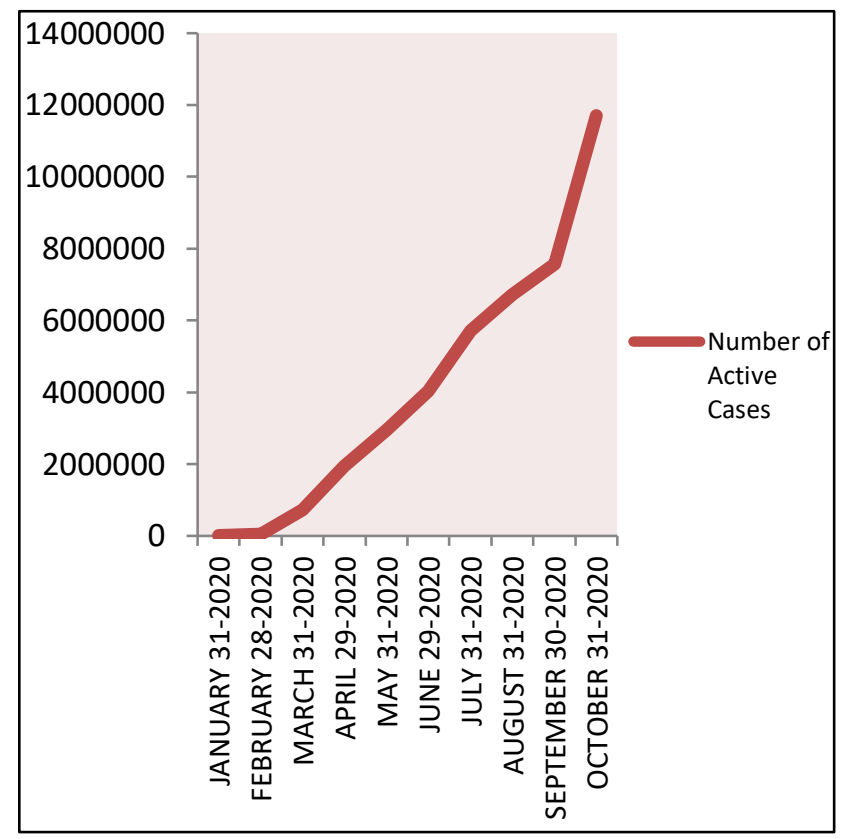

Figure 1: Number of active cases worldwide.

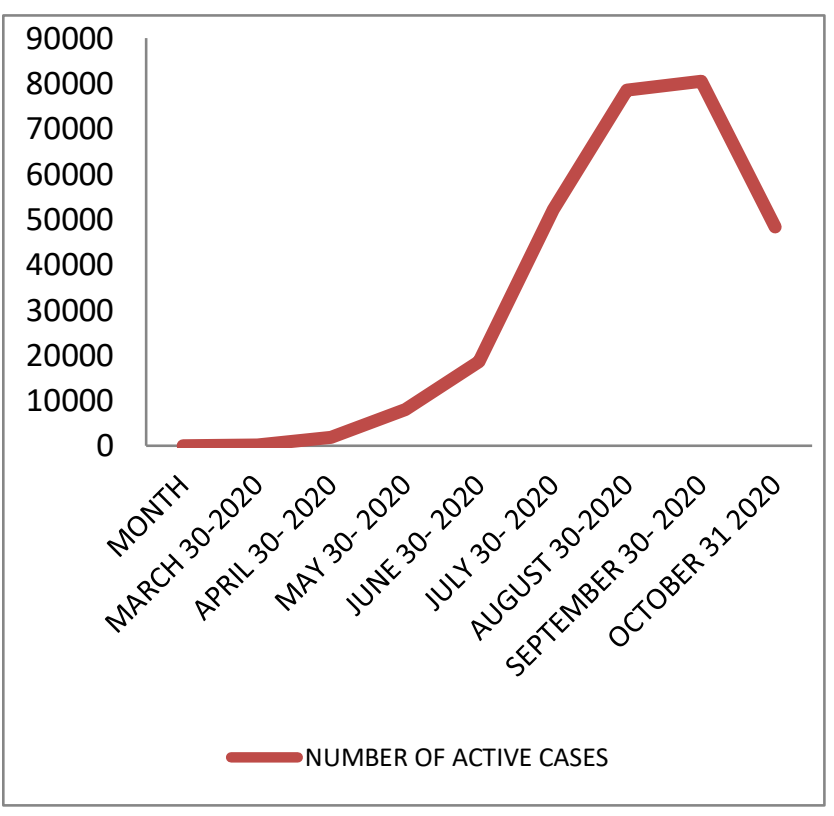

Figure 2: Number of active cases in India.

\section{SOURCE AND MODE OF TRANSMISSION}

Coronavirus belongs to a large family of viruses present in various animal species including, dromedary camels, wild cats, and bats. During the epidemic outburst of SARS and MERS, it had been pointed out that the infections had originated among cats and dromedary camels respectively. Belatedly, advanced virological and genetic examination revealed that bats were the reservoir hosts for both SARS$\mathrm{CoV}$ and MERS-CoV. Investigations had revealed the existence of four genera of corona viruses, $\alpha$-coronavirus, $\beta$-coronavirus, $\gamma$-coronavirus, and $\delta$-coronavirus among which $\alpha$ and $\beta-\mathrm{CoV}$ s are from bats and $\gamma$ and $\delta-\mathrm{CoV}$ s are most probably from birds. ${ }^{2}$

The source of outbreak was reported from the Hunan seafood market located in Wuhan city since positive environmental samples of SARCoV2 were identified from the same. ${ }^{3}$ Since the first outburst, it was obvious that disease transmission progressed from human to human, as the newly infected patients did not have a history of connection with the market place.

Human to human transmission: It occurs in multiple ways, through contact transmission or fomite transmission, droplet transmission, and airborne transmission, wherein infection spread through exposure with virus-containing respiratory droplets and smaller droplets remain suspended in air over a long time and long-distance ( $>6$ feet) produced through coughing and sneezing. ${ }^{4}$ Studies have shown that COVID-19 can stay agile from several hours to days on surfaces. These viruses are discernible for up to 3 hours in aerosols, 4 hrs on copper items, up to 24 hours on cardboard, and 2-3 days on plastic and stainless-steel items. ${ }^{5}$ The virus is passed on through the air from the individuals who closely interact with the patients (less than $2 \mathrm{~m}$ ). Therefore, it is recommended to cover cough and sneeze. The use of protective mask and alcohol-based sanitizers helps to prevent the spread of the viruses. ${ }^{6}$

Transmission through food: Despite of no evidence on the spread of the virus through foodstuffs, preventive methods should be taken. The FDA mentions the compliance with 4 essential steps of food safety to prevent foodborne illness which may apply to coronavirus as well ${ }^{7}$ : Clean, separate, cook well and chill.

\section{CLINICAL ADVANCEMENT AND DIAGNOSIS}

People infected with COVID-19 may have common symptoms associated with respiratory infections such as hyperthermia, tussis, and cephalalgia. There are no peculiar symptoms. Clinical manifestations may range from asymptomatic to severe pneumonia and death. The clinical manifestations include hyperthermia, nonproductive cough, fatigue, shortness of breath, sore throat, chills, headache, vomiting, nasal congestion, hemoptysis, and conjunctival congestion.

Most of the patients experience mild to moderate disease. In serious cases, patients may experience severe dyspnea, very low blood oxygen saturation $(<93 \%), \mathrm{PaO}_{2} / \mathrm{FiO}_{2}$ ratio $<300$ with or without greater than $50 \%$ of lung infiltrates within 1-2 days. A certain number of patients also contact life-threatening illnesses such as septicemia and multiorgan dysfunction. ${ }^{8}$ 


\section{Laboratory testing}

\section{NAAT (nucleic acid amplification test)}

This test is based on detecting the unique sequence of viral mRNA using real-time reverse-transcription polymerase chain reaction (rRT-PCR). This diagnostic test is said to be positive if: At least one out of two different targets on the COVID-19 virus genome is specific using a validated assay. (or) one positive NAAT confirms the presence of $\beta$ coronavirus and/or COVID-19.

In case a negative result is obtained from a person with a high index of suspicion for COVID-19, a lower respiratory tract sample should also be collected in addition to the upper respiratory tract sample and tested if possible. ${ }^{9}$

\section{Serological testing}

Although quantitative reverse transcriptase-PCR remains the most widely used diagnostic test for coronavirus SARS-CoV2 it is not devoid of drawbacks which include cost, higher time consumption, and false negatives which can arise due to not properly handling the nucleic acid samples. Another problem with qRT-PCR is that among infected persons it ceases to give positive results 14 days post-infection (post manifestations of symptoms). A viable alternative to qRT-PCR is immunoassays which are relatively cheap and capable of detecting infection after 14 days of symptom onset. Immunoassays target specific immunogenic proteins of the coronavirus such as the spike protein (which is the most exposed viral protein), the $\mathrm{N}$ protein (a large quantity of which is expressed during infection), another target is the receptor-binding domain (RBD), lies along with the S protein. The specificities and sensitivities of these tests remain an important factor when selecting the target protein, as several of the fore mentioned proteins cross-react with other coronaviruses such as SARS-CoV and MERS CoV. The IgM antibodies produced against the target protein become detectable as early as 3 days post-infection and peak around 2-3 weeks and can even be detected 1 month after the onset of the infection. Other classes of antibodies i.e., IgAs and IgGs are detected as early as 4 days and peaks within 2 weeks approximately. Thus, immunoassays can help in identifying exposed individuals who could not be detected. ${ }^{10}$

\section{Differential diagnosis}

The symptoms of COVID-19 are usually similar to those seen for the common cold and flu. The severity of the illness ranges from mild to severe. The symptoms develop within a span of 2 to 14 days after the viral exposure. The symptoms include fever, cough, and dyspnea. Since these symptoms are very similar to that of cold and flu, additional criteria like recent travel to any affected countries or exposure to an infected individual are also considered while screening the patients. The differential diagnosis can be very broad hence; rapid respiratory viral panel via a nasopharyngeal swab will help to detect the respiratory virus. If further clarifications are warranted, a chest CT (computed tomography) may be obtained. ${ }^{11}$

The viral infection can be provisionally diagnosed based upon the signs and symptoms with the confirmation being done by quantitative reverse transcriptase polymerase chain reaction (qRT-PCR) of infected secretions. Although the test has a high specificity, the sensitivity can be quite low ranging from $60-70$ to $95-97 \%$ depending on the country.

CT findings have been used as a surrogate diagnostic test. Many viral pneumonia cases were reported in China (Wuhan) in late December 2019, afterwards, it was determined to be affected by a novel coronavirus, SARS Coronavirus 2 (SARS- CoV2, previously known as 2019nCov). The genomic pattern of SARS-COV2 is distinct from those of other corona viruses. ${ }^{12}$

CT findings helps in diagnosing and managing the patients with COVID-19 pneumonia. The evolution of the disease is not well understood through CT findings. After further studies, it was suggested that $\mathrm{CT}$ is a sensitive modality to detect COVID-19 pneumonia even in asymptomatic individuals and it should be considered as a screening tool together with RT- PCR when a patient has a traveling history or direct contact with infected individuals. Although it is effective to an extent, more studies are required to correlate $\mathrm{CT}$ findings with the severity and progression of disease. ${ }^{13}$

\section{PATHOGENESIS}

The infection is generally transmitted through the respiratory droplets produced by an infected individual through coughing and sneezing. Patients can also become asymptomatic carriers where the infected individual has the potential to spread the disease in the asymptomatic state. This is particularly bothersome as the individual itself is unaware of the infection leading to suboptimal measures taken by the individual to prevent the spread of the infection which otherwise would have been undertaken had the knowledge of the infection been known. ${ }^{13}$

Coronavirus is a positive-sense single-stranded RNA virus. They consist of four main structural protein which includes the spike $(\mathrm{S})$, membrane $(\mathrm{M})$, envelope $(\mathrm{E})$, and nucleocapsid $(\mathrm{N})$, with all being encoded in the 3 ' end of viral genome. ${ }^{14}$ The $S$ protein binds to the specific receptor, ACE-2 and releases the RNA to the cytoplasm and replicates with the help of suitable enzymes and cause damage to the type 2 pneumocytes. ${ }^{15,16}$ The replicating virus primarily targets the respiratory system (nasal cavity, trachea, bronchi, and lung lobe). As the disease progresses, lesion develops in the pulmonary tissue involving alveoli and bronchioles which leads to alveolar edema. The gaseous exchange capacity of the lungs gets impeded as the alveoli get progressively damaged, eventually leading to hypoxemia. ${ }^{17}$ 


\section{MANAGEMENT}

Several vaccine candidates are being evaluated at present for the virus and currently, there is no vaccine approved for use to prevent COVID-19 infection. ${ }^{18}$

\section{Pharmacological therapy}

Although it may be years before we have SARS-CoV2 specific antiviral drugs, existing host-directed therapies are found to be safe and clinically proven to reduce immunopathology. ${ }^{19}$

\section{Hydroxychloroquine and chloroquine}

Hydroxyl chloroquine, belongs to 4-aminoquinoline class. Hydroxychloroquine has related or even the same pharmacokinetics to chloroquine, with rapid gastrointestinal absorption, a large volume of distribution as well as elimination by the kidneys. Cytochrome p450 enzymes (CYP2D6, 2C8, 3A4 and 3A5) metabolizes hydroxychloroquine to $\mathrm{N}$-desethylhydroxychloroquine. ${ }^{20}$

Chloroquine is recently known as a potential broad antiviral drug. It is identified to stop viral infection by raisin the endosomal $\mathrm{pH}$ necessary for virus/ cell fusion and getting involved with SARS- cell receptor glycosylation. Upon oral management, it has a vast distribution characteristic throughout the entire body. Chloroquine and hydroxychloroquine inhibit CYP2D6 activity and may interact with other medications that depend on these enzymes. ${ }^{21}$

\section{Dexamethasone}

The COVID -19 treatment guideline panel recommends using dexamethasone (at a dose of $6 \mathrm{mg}$ per days) for the treatment of COVID-19 in patients who are mechanically ventilated (AI) and in patients who require supplemental oxygen but who are not mechanically ventilated (BI). Dexamethasone is a moderate cytochrome P450 (CYP)3A4 inducer. As such, it may reduce the concentration and potential efficacy of concomitant medications that are CYP3A4 substrates. Clinician's should review the patient's medication regimens to assess potential interactions. ${ }^{22}$

Dexamethasone is beneficial in some patients, but it is not beneficial for the patients in the second stage of illness. Findings from an analysis of post hoc subsets suggested that in older age groups dexamethasone failed to show its action and the positive outcome is less in patients suffering from diabetes. ${ }^{23}$

\section{Interferons}

Interferons are the proteins produced by the cells in response to an infection. Insufficient or inappropriately timed activation of interferon signaling may contribute to severe cases of COVID-19, which is caused by the coronavirus SARS-CoV-2. Researchers measured protein is important in regulating the immune response in the serum of hospitalized COVID-19 patients and patients with respiratory issues that were not related to COVID-19. The proteins measured are chemokines and cytokines. They act as signaling immune cells or lead to immune responses. ${ }^{24}$

Nevertheless, interferon $\beta$ tends to have the most potent inhibitory in-vitro effect against MERS-CoV as compared to interferon $\alpha$. When in use of ribavirin alone or when it combined with interferon $\alpha$, it reflects a mild anti-MERS$\mathrm{CoV}$ effect in vitro. ${ }^{25}$

\section{Nucleoside analogues}

Nucleoside and nucleotide analogues can be used to prevent viral replication in infected cells. Nucleoside analogues appear to target viral replication, particularly viral DNA or RNA polymerase, and have been clinically effective for treating viral infections. Even though nucleoside analogues such as BCX4430 inhibit CoVs, some previously tested nucleoside analogues have been unable to effectively inhibit $\mathrm{CoV}$ replication and others have shown weak indexes of selectivity. ${ }^{26}$

\section{Remdesivir}

Remdesivir is a broad-spectrum antiviral agent. Remdesivir is an adenosine analogue that incorporates into nascent viral RNA chains and leads to premature termination, resisting virus replication. The evaded viral exonuclease proof-reading results in decreased development of viral RNA. Recently, remdesivir is a drug undergoing a clinical trial. ${ }^{27,28}$

Wang et al suggested that remdesivir blocks RNA dependent RNA polymerase enzyme in low micromolar SARS-CoV2 concentrations and has a high selectivity index. On 4 February 2020, medical researchers in China declared that darunavir prevents invitro SARS-CoV-2 infection. Cellular related studies suggested that darunavir remarkably suppresses the viral replication at a concentration of $300 \mu \mathrm{M}$ invitro with an inhibition output of 280 times than that of the untreated community. ${ }^{29}$

\section{Ribavirin-interferon combination}

Invitro studies revealed that anti-MERS-CoV activity is present in interferon and ribavirin. With the subsequent use of ribavirin and interferons invitro activities were improved. All present medications have individual virucidal effects at high doses, while the combination of Ribavirin and interferon $\alpha-2 b$ had a synergetic virucidal effect at lower doses with lesser toxicity. Studies conducted in animals had shown some prophylactic impact in minimizing disease incidence in pre-treated animals. ${ }^{30}$ In vivo studies, the combination of interferon-alpha $2 \mathrm{~b}$ (INF- $\alpha 2 b$ ) and ribavirin had an 8-fold decline in the dose of INF- $\alpha 2 b$ and 16 -fold decline in the dose of ribavirin. ${ }^{31}$ 


\section{Ribavirin-corticosteroid combination}

The treatment with ribavirin-corticosteroid combination focuses to prevent the community spread. Mostly prescribed corticosteroids include, glucocorticoids, prednisolone and antiviral medications includes darunavir, cobicistat, remdesivir, favipiravir, triazavirin, interferon. Along with these therapies M1 macrophage suppression may also find to be helpful. Alternative therapies include hydrogen-oxygen nebulizer and electrotherapy with ultrashort-wave dietary may help. ${ }^{32}$

\section{Favipiravir and tocilizumab combination}

Recent studies suggested that combination of favipiravir and tocilizumab can significantly improve COVID-19 pulmonary inflammation and can reduce the mortality. Since Favipiravir is a teratogen, it should be avoided in pregnant women. ${ }^{33}$

\section{MANAGEMENT OF COVID-19 IN SPECIAL POPULATION}

\section{Pediatric patients}

Bed rest with adequate calorie and water intake is necessary. Oxygen therapy should be provided for hypoxic patients and antibiotics if any bacterial co-infection.

Currently, no FDA-approved drugs or biological agents are available for the prevention and management of novel coronavirus, thus FDA has given emergency use authorization for remdesivir in patients with severe SARSCoV2. Dosing should be done based on pharmacokinetic data from adult healthy volunteers. ${ }^{34}$

\section{Asthma}

Advice all patients with asthma to continue their asthma medications without fail. Avoid the use of nebulizers, if there is a risk for aerosolization of the novel coronavirus, thus it is recommended to use pressurized metered-dose inhalers with spacer and face mask if possible. Avoid spirometry in suspected/confirmed COVID-19 patients. Stringent contamination control measures should be followed during intubating, nebulizer therapy, oxygen therapy, non-invasive ventilating. ${ }^{35}$

\section{Cancer and end-stage renal disease}

For hematological malignancies, consider reducing immunosuppressive agents or dosing of chemotherapy, if possible. Patients with ESRD awaiting transplantation can be treated with methylprednisolone along with prophylactic antibiotics therapy, maximum mechanical ventilation, and withdrawal of immunosuppressive therapy. ${ }^{36}$

\section{Pregnant patients}

Alpha-interferon, lopinavir/ritonavir, and chloroquine can be prescribed safely in primigravid patients. Interferonalpha is a wide-spectrum anti-viral drug, effective in limiting the viral replication in vitro and in vivo, with no significant risk of adverse perinatal outcome.

Chloroquine, an antimalarial drug was found to effective in SARS Cov-2 and is also not associated with problems in the growth, or development of newborns, neurological development, birth weight, gestational age, and visual acuity in infants.

Remdesivir and Arbidol have also been found to be effective, but data regarding its safety in pregnancy is lacking. ${ }^{37}$

\section{HIV patients}

The antiretroviral medications like lopinavir/ritonavir are used for the management of novel coronavirus, it is not recommended to switch in the regimen for prevention and treatment in HIV patients. It has been found that patients who are already receiving antiretroviral therapy for existing HIV infection might have reduced susceptibility towards COVID-19 infection or the severity of COVID-19 might be much lower if acquired. ${ }^{38}$

\section{Neurological conditions}

Patients with multiple sclerosis (MS) may have transient exacerbation (pseudo-relapse) due to acute infection. In such cases, screening should be conducted for patients showing active symptoms before initiating corticosteroid therapy. While starting with corticosteroids, consider a high-dose oral regimen to reduce the need for hospital admission. Disease-modifying therapies (DMT) should only be initiated considering its potential immunosuppressive action. For geriatric patients and in patients having a progressive MS DMTs may be inefficient and comorbidities may elevate the severity of novel coronavirus. In multiple sclerosis patients with mild symptoms, it is not recommended to stop 1st line DMTs. Infusions and cladribine administration should be withheld until symptoms resolve. In patients showing severe symptoms, it is recommended to stop all injectables, infusions, and other medications and should restart within 8 weeks if possible, to avoid the recurrence of MS. It is recommended to provide minimum monitoring in patients with high COVID-19 risk. ${ }^{39}$

\section{CONVALESCENT PLASMA THERAPY}

For managing the infection, the main focus is given to infection prevention, case detection and monitoring, and supportive care. Convalescent plasma therapy is used to improve the patient's survival rate who has not been responding well to the available treatment. Evidence shows that the convalescent plasma taken from the patient, 
who has been recovered from the viral infection can be used to treat an infected patient without any further complications. So, the safety of this therapy must be accomplished. ${ }^{40}$

\section{VACCINE DEVELOPMENTS}

A combination of conventional and next-generation techniques is required for the development of COVID-19 vaccine. By considering the safety reasons live vaccines will not be attempted in patients suffering from COVID19 but preclinical trials have been attempted in primates using inactivated whole virus vaccines. Earlier stages of vaccine development were crucial, it involves the identification of antigens (natural or synthetic) depending on the viral protein. ${ }^{41}$ Phase 1-Phase 2 clinical trials were conducted using inactivated vaccines. Other vaccine strategies include spike protein injections with DNA coding for spike protein. According to WHO, the SARSCOV2 virus is responsible for the outbreak of COVID 19, and against SARS-COV2, 70 vaccines are in progress, and among those 3 vaccines are in clinical trials.

\section{PREVENTION AND CONTROL}

Although risks of factors for COVID-19 are still unknown, it is expected the transmission of the virus is from live infected animals to human beings. Infected snakes and cats are found as carriers to transmit the virus to a lesser extent. All of the three beta coronaviruses became prominent through the zoonotic transmission. ${ }^{42}$

Parallels can be made between SARS and COVID-19, China shares common features of these two, and similar circumstances provides an explosive spread of these viruses, involving exposure to freely living live animals on open markets, overpopulated places or places where people gathered beyond the limits and lack of health services. MERS and COVID-19 share the similarities in that cases will be asymptomatic later on it start to spread quickly even to a great extent. ${ }^{43}$

Understanding the awareness, attitudes, and practice (KAP) of hand washing among health care professionals is important for bringing about a lasting shift in person and institutional behavior and enhancing these practices when developing interventions. Hand hygiene is an important factor and it includes behavioral hand hygiene attitude, perceived social norm, perceived behavioral control, awareness on the risk of infection, frequent sanitation, perceived role model, adequate awareness, and strongmotivation. ${ }^{44}$

\section{CONCLUSION}

Globally spreading pandemic COVID 19, developed in Wuhan, China, and is expected to be transmitted from animals to humans. The symptoms of COVID 19 include fever, high-grade temperature, shortness of breath, soreness in the throat, pneumonia, etc. Within 3rd July
2020, COVID 19 consumed more than 200 countries and territories. Currently, the vaccine for COVID 19 is under trials and exact anti-viral therapies are not available. Meanwhile, COVID 19 is treated symptomatically. Based on some study reports, medications including lopinavir/ritonavir combination therapy, remdesivir, darunavir, ribavirin, interferon could successfully treat COVID-19. Convalescent plasma therapy is also used in some serious cases, but its safety must be accomplished. Properly following preventive measures like social distancing, wearing masks and gloves, hand sanitation, and maintaining personal hygiene can help in preventing the further spread of this infection.

\section{Funding: No funding sources \\ Conflict of interest: None declared \\ Ethical approval: Not required}

\section{REFERENCES}

1. Dhama K, Sharun K, Tiwari R, Sircar S, Bhat S, Malik YS et al. Coronavirus disease 2019-COVID-19.

2. Sahin AR, Erdogan A, Agaoglu PM, Dineri Y, Cakirci AY, Senel ME et al. 2019 Novel Coronavirus (COVID-19) Outbreak: A Review of the Current Literature. EJMO. 2020;4(1):1-7.

3. She J, Jiang J, Ye L, Hu L, Bai C, Song Y. 2019 novel coronavirus of pneumonia in Wuhan, China: emerging attack and management strategies. CTM. 2020;9(1):1-7.

4. Johnson HC, Gossner CM, Colzani E, Kinsman J, Alexakis L, Beauté $\mathrm{J}$ et al. Potential scenarios for the progression of a COVID-19 epidemic in the European Union and the European Economic Area, March 2020. Eurosurveillance. 2020;25(9).

5. Van Doremalen N, Bushmaker T, Morris DH, Holbrook MG, Gamble A, Williamson BN et al. Aerosol and Surface Stability of SARS-CoV-2 as Compared with SARS-CoV-1. NEJM. 2020;382:1564-7.

6. Chan JF, Yuan S, Kok KH, To KK, Chu H, Yang J et al. A familial cluster of pneumonia associated with the 2019 novel coronavirus indicating person-to-person transmission: a study of a family cluster. Lancet. 2020;395(10223):514-23.

7. Bosch A, Gkogka E, Le Guyader FS, Loisy-Hamon F, Lee A, Van Lieshout L et al. Foodborne viruses: Detection, risk assessment, and control options in food processing. Int. J. Food Microbiol. 2018;285:110-28.

8. Mission WC. Report of the WHO-China Joint Mission on Coronavirus Disease 2019 (COVID-19). Geneva 2020.

9. Binnicker MJ. Emergence of a Novel Coronavirus Disease (COVID-19) and the Importance of Diagnostic Testing: Why Partnership between Clinical Laboratories, Public Health Agencies, and Industry Is Essential to Control the Outbreak. Clin Chem. 2020;66(5):664-6. 
10. Amanat F, Nguyen T, Chromikova V, Strohmeier S, Stadlbauer D, Javier A et al. A serological assay to detect SARS-CoV-2 seroconversion in humans. medRxiv. 2020;2.

11. Bordi L, Nicastri E, Scorzolini L, Di Caro A, Capobianchi MR, Castilletti C et al. Differential diagnosis of illness in patients under investigation for the novel coronavirus (SARS-CoV-2), Italy, February 2020. Euro surveillance. 2020;25(8).

12. Ai T, Yang Z, Hou H, Zhan C, Chen C, Lv W et al. Correlation of chest CT and RT-PCR testing in coronavirus disease 2019 (COVID-19) in China: a report of 1014 cases. Radiol. 2020:200642.

13. Shi H, Han X, Jiang N, Cao Y, Alwalid O, Gu J et al. Radiological findings from 81 patients with COVID19 pneumonia in Wuhan, China: a descriptive study. Lancet Infect Dis. 2020;20(4):425-34.

14. Bosch BJ, Van der Zee R, De Haan CA, Rottier PJ. The coronavirus spike protein is a class I virus fusion protein: structural and functional characterization of the fusion core complex. J Virol. 2003;77(16):880111 .

15. Lu R, Zhao X, Li J, Niu P, Yang B, Wu H et al. Genomic characterisation and epidemiology of 2019 novel coronavirus: implications for virus origins and receptor binding. Lancet. 2020;395(10224):565-74.

16. Rockx B, Kuiken T, Herfst S, Bestebroer T, Lamers M, De Meulder D et al. Comparative Pathogenesis Of COVID-19, MERS And SARS In A Non-Human Primate Model. bioRxiv. 2020.

17. Zumla A, Hui DS, Azhar EI, Memish ZA, Maeurer M. Reducing mortality from 2019-nCoV: host-directed therapies should be an option. Lancet. 2020;395(10224):e35-6.

18. Lu H. Drug treatment options for the 2019-new coronavirus (2019-nCoV). Bio sci Trends. 2020;14(1):69-71.

19. Beigel JH, Nam HH, Adams PL, Krafft A, Ince WL, El-Kamary SS et al. Advances in respiratory virus therapeutics-A meeting report from the $6^{\text {th }}$ isirv Antiviral Group conference. Antiviral res. 2019;167:45-67.

20. Ibanez S, Martinez O, Valenzuela F, Silva F, Valenzuela O. Hydroxychloroquine and chloroquine in COVID-19: should they be used as standard therapy? Clin Rheumatol. 2020;3:1.

21. Wang M, Cao R, Zhang L, Yang X, Liu J, Xu M et al. Remdesivir and chloroquine effectively inhibit the recently emerged novel coronavirus (2019-nCoV) in vitro. Cell research. 2020;30(3):269-71.

22. Singh AK, Majumdar S, Singh R, Misra A. Role of corticosteroid in the management of COVID-19: A systemic review and a Clinician's perspective. Diabetes and Metabolic Syndrome. Clin Res Reviews. 2020;14(5):971-8.

23. Johnson RM, Vinetz JM. Dexamethasone in the management of COVID-19. BMJ. 2020;370:m2648.
24. Jalkanen J, Hollmen M, Jalkanen S. Interferon beta1a for COVID-19: critical importance of the administration route. Crit Care. 2020;24(1):1-3.

25. Omrani AS, Saad MM, Baig K, Bahloul A, AbdulMatin M, Alaidaroos AY et al. Ribavirin and interferon alfa-2a for severe Middle East respiratory syndrome coronavirus infection: a retrospective cohort study. Lancet Infect Dis. 2014;14(11):1090-5.

26. Agostini ML, Andres EL, Sims AC, Graham RL, Sheahan TP, Lu X.et al. Coronavirus susceptibility to the antiviral remdesivir (GS-5734) is mediated by the viral polymerase and the proofreading exoribonuclease. MBio. 2018;9(2):e00221-18.

27. Warren T, Jordan R, Lo M, Soloveva V, Ray A, Bannister R et al. Nucleotide prodrug GS-5734 is a broad-spectrum filovirus inhibitor that provides complete therapeutic protection against the development of Ebola virus disease (EVD) in infected non-human primates. Infect Dis. 2015;2(1):LB2.

28. Liu W, Morse JS, Lalonde T, Xu S. Learning from the past: possible urgent prevention and treatment options for severe acute respiratory infections caused by 2019-nCoV. Chembiochem. 2020;21(5):730-8.

29. Dong L, Hu S, Gao J. Discovering drugs to treat coronavirus disease 2019 (COVID-19). Drug Discoveries Therap. 2020;14(1):58-60.

30. Khalid M, Al Rabiah F, Khan B, Al Mobeireek A, Butt TS, Al Mutairy E. Case report Ribavirin and interferon- $\alpha 2 b$ as primary and preventive treatment for Middle East respiratory syndrome coronavirus: a preliminary report of two cases. Antiviral therapy. 2015;20:87-91.

31. Khalili JS, Zhu H, Mak NS, Yan Y, Zhu Y. Novel coronavirus treatment with ribavirin: Groundwork for an evaluation concerning COVID-19. J med virol. 2020;10.1002/jmv.25798.

32. Chan KW, Wong VT, Tang SC. COVID-19: An Update on the Epidemiological, Clinical, Preventive and Therapeutic Evidence and Guidelines of Integrative Chinese-Western Medicine for the Management of 2019 Novel Coronavirus Disease. Am J Chinese Med. 2020:1-26.

33. Thammathiwat $\mathrm{T}$, Tungsanga $\mathrm{S}$, Tiankanon $\mathrm{K}$, Torvorapanit P, Chumpangern W, Udomkarnjananun S, et al. A Case of Successful Treatment of Severe COVID-19 Pneumonia with Favipiravir and Tocilizumab in Post-kidney Transplant Recipient. Transplant Infect Dis. 2020:e13388.

34. Tagarro A, Epalza C, Santos M, Sanz-Santaeufemia FJ, Otheo E, Moraleda C et al. Screening and severity of coronavirus disease 2019 (COVID-19) in children in Madrid, Spain. JAMA pediatrics. 2020;e201346.

35. Licskai C, Yang CL, Ducharme FM, Radhakrishnan D, Podgers D, Ramsey C et al. Addressing therapeutic questions to help Canadian physicians optimize asthma management for their patients during the COVID-19 pandemic. Canad J Respiratory Crit Care Sleep Med. 2020:1-4. 
36. Huang J, Lin H, Wu Y, Fang Y, Kumar R, Chen G et al. COVID-19 in post-transplantation patients-report of two cases. Am J Transplant. 2020;3:10.

37. Mei Y, Luo D, Wei S, Liao X, Pan Y et al. Obstetric Management of COVID-19 in Pregnant Women. Frontiers Microbiol. 2020;11:1186.

38. Alinaghi S, Ghadimi M, Hajiabdolbaghi M, et al. Prevalence of COVID-19-like symptoms among people living with HIV, and using antiretroviral therapy for prevention and treatment. Curr HIV Res. 2020;18(5):373-80.

39. Giovannoni G, Hawkes C, Lechner-Scott J, Levy M, Waubant E, Gold J. The COVID-19 pandemic and the use of MS disease-modifying therapies. Multiple Sclerosis Rel Disord. 2020;39:102073.

40. Chen L, Xiong J, Bao L, Shi Y. Convalescent plasma as a potential therapy for COVID-19. Lancet Infect Dis. 2020;20(4):398-400.

41. Jin Y, Yang H, Ji W, Wu W, Chen S, Zhang W et al. Virology, epidemiology, pathogenesis, and control of COVID-19. Viruses. 2020;12(4):372.
42. Peeri NC, Shrestha N, Rahman MS, Zaki R, Tan Z, Bibi $S$ et al. The SARS, MERS and novel coronavirus (COVID-19) epidemics, the newest and biggest global health threats: what lessons have we learned? Int J Epidemiol. 2020;49(3):717-26.

43. Rothe C, Schunk M, Sothmann P, Bretzel G, Froeschl G, Wallrauch C et al. Transmission of 2019-nCoV infection from an asymptomatic contact in Germany. N Engl J Med. 2020;382(10):970-71.

44. Alfahan A, Alhabib S, Abdulmajeed I, Rahman S, Bamuhair S. In the era of corona virus: health care professionals' knowledge, attitudes, and practice of hand hygiene in Saudi primary care centers: a crosssectional study. J. Community Hosp. Intern. Med. Perspect. 2016;6(4):32151.

Cite this article as: Shaji B, Suresh A, Vasanth N, Stanly SM. A recent review on 2019 novel coronavirus outbreak. Int J Basic Clin Pharmacol 2021;10:140-7. 